\title{
Poly(styrene-b-acrylic acid) Nanoparticles with High Magnetic Loading for Magnetic Hyperthermia Cancer Therapy
}

\author{
Chariya Kaewsaneha ${ }^{\mathrm{a},{ }^{*}}$, Abdelhamid Elaissari ${ }^{\mathrm{b}}$, Pakorn Opaprakasit $^{\mathrm{a}}$, Paiboon Sreearunothai ${ }^{\mathrm{a}}$ \\ and Pramuan Tangboriboonrat ${ }^{\mathrm{c}}$
}

${ }^{a}$ School of Bio-Chemical Engineering and Technology, Sirindhorn International Institute of Technology (SIIT), Thammasat University, Pathum Thani 12121, Thailand

${ }^{b}$ Univ Lyon, University Claude Bernard Lyon-1, CNRS, ISA-UMR 5280, F-69622 Lyon, France

${ }^{c}$ Department of Chemistry, Faculty of Science, Mahidol University, Rama 6 Road, Phya Thai, Bangkok 10400, Thailand Corresponding Author's E-mail: chariya@siit.tu.ac.th

\begin{abstract}
Magnetic polymeric nanoparticles (MPNPs), a cluster of magnetic nanoparticles (MNPs) or superparamagnetic iron oxide nanoparticles (SPIONPs) embedded into a poly(styrene $27-b$-acrylic acid $\left.{ }_{120}\right), \mathrm{P}\left(\mathrm{S}_{27}-b-\mathrm{AA}_{120}\right)$ particle, were prepared via a one-step chemically-mild method. By controlling the type of solvent for MNPs, and the balance between the magnetic loading at a weight fraction of $70 \mathrm{wt} \%$, and the $\mathrm{P}\left(\mathrm{S}_{27}-b-\mathrm{AA}_{120}\right)$ contents in a range of $0.1-0.5 \mathrm{wt} \%$, promoted the formation of well-defined MPNPs while achieving high OAMNP loading. The MPNPs were generated via induced co-self-assembly mechanism of hydrophobic interactions between oleic acid (OA) coated on MNPs and the PS segments of the block copolymer. Without the use of a surfactant or crosslinking agent, high stability of MPNPs in an aqueous medium was achieved from the contribution of long hydrophilic PAA blocks
\end{abstract}


containing carboxylic groups. Due to the high superparamagnetic nanoparticles loading, monodispersity, and high stability, the as-prepared MPNPs are highly responsive to an external magnetic field, and can efficiently generate heat under the application of an alternating magnetic field (AMF). The as-prepared MPNPs have a high potential for use as magnetic hyperthermia for cancer therapy applications.

Keywords: Magnetic polymeric nanoparticle, Amphiphilic block copolymer, Self-assembly, Poly(styrene- $b$-acrylic acid), Magnetic hyperthermia, Cancer therapy

\section{INTRODUCTION}

Magnetic polymeric nanoparticles (MPNPs), consisting of a cluster of superparamagnetic iron oxide nanoparticles (SPIONPs) embedded into a polymer particle, are useful in biomedical applications. For example, they are used in magnetic resonance imaging $(\mathrm{MRI})^{1}$, diagnostics ${ }^{2}$, controlled drug delivery $^{3}$, and hyperthermia materials for cancer therapy. ${ }^{4,5}$ Magnetic hyperthermia has been a promising therapeutic concept for malignant cancer treatment by utilizing the heat generated by the magnetic nano-mediators when subjected to an external alternating magnetic field (AMF). Generally, magnetic hyperthermia therapy primarily involves the raising of tumor local temperature within a range of $43-46{ }^{\circ} \mathrm{C}$, resulting in the changed physiology of the cancer cells, which eventually leads to their apoptosis/necrosis. ${ }^{6,7}$ Although SPIONPs are widely used in hyperthermia investigations, small sized SPIONPs have limitations on these multi-modality bio-related applications, while large size MPNP in a range of 100-200 $\mathrm{nm}$ are desired for many biomedical applications, thereby facilitating high cellular uptake and prolonged circulation in the blood stream. ${ }^{8}$ To make magnetic hyperthermia clinically useable and cancer eradication feasible, it is essential that sufficient heat must be delivered within the whole tumor mass while leaving the surrounding 
normal tissue unaffected. Using controlled MPNPs with high SPIONP loading results in a considerable increase in the rate of AMF-induced heating within the tumor, which gives a fast magnetic response. Xue et al. reported that the inductive heating property of alginate-chitosan microspheres loaded with high concentrations of $14-\mathrm{nm}$ SPIONPs $\left(0.5 \mathrm{mg} \cdot \mathrm{mL}^{-1}\right)$ was remarkably more efficient than that of low SPIONPs loadings. ${ }^{9}$ This was based on the evidence that the time required to raise the temperature to $42{ }^{\circ} \mathrm{C}$ of the high-loading SPIONPs was significantly shorter than those of low-loading SPIONPs.

Among various techniques used for fabricating MPNPs, e.g., conventional emulsion $^{10}$, miniemulsion ${ }^{11,12}$, microemulsion $^{13}$, and seed-emulsion polymerization ${ }^{14-16}$, a miniemulsion and/or seed emulsion polymerization have been claimed to effectively provide high magnetic loading. By using a mini-EP, the resulting MPNPs $(\sim 200 \mathrm{~nm})$ that are functionalized with carboxylic groups from acrylic acid show a uniform distribution of OAMNPs (53 wt\%) in a poly(styrene/divinylbenzene/acrylic acid) (P(St/DVB/AA) matrix. ${ }^{9,10,15}$ Similarly, similar MPNPs functionalized with polyelectrolyte brush (PAA) were prepared by using two-step of miniemulsion and photoemulsion polymerization. ${ }^{18}$ The thickness of particle shells could be controlled by the dose of monomer AA. For SEP, the formation of magnetic clusters occurs prior to being encapsulated by the polymer matrix. ${ }^{14-16,19}$ The content of magnetic substances inside a polymer particle can be controlled at the beginning of magnetic seed emulsion (an organic ferrofluid of OA-MNPs emulsified in an aqueous medium by Triton X-405). Then, styrene and DVB monomers containing a 2,2'-azobis (2-isobutyronitrile) initiator were diffused inside the magnetic seed emulsion before being polymerized. Although MPNPs with a high magnetic content of $>60 \mathrm{wt} \%$ were produced, such techniques require multiple washing steps to isolate the purified products. Moreover, complicated in situ chemical or polymerization techniques are time-consuming. 
Facile self-assembly of amphiphilic block copolymers (ABCs) and NPs is offered as a powerful route to the formation of hybrid MPNPs. ${ }^{20-23}$ Generally, ABCs with long hydrophobic blocks and hydrophobic NPs or MNPs are dispersed in their good solvents. After switching from a good solvent to a non-solvent, a hybrid particle is formed via a nucleationaggregation mechanism. The hydrophilic segments of the $\mathrm{ABC}$ allow a transfer of $\mathrm{NP}$ aggregates into a reservoir of the copolymer's hydrophobic segments. Both NPs and ABCs can be precipitated as spherical particles whose surface energy is minimized. The formation of hybrid particles can be controlled by several factors e.g., the hydrophobic-to-hydrophilic relative block length of the copolymer, the polymer concentration, the solvent nature, and the solvent/water ratio. A process for preparing hybrid MPNPs via the self-assembly method using poly(styrene $250-b$-acrylic acid 13$), \mathrm{P}\left(\mathrm{S}_{250}-b\right.$-AA 13$)$, and $\gamma-\mathrm{Fe}_{2} \mathrm{O}_{3} \mathrm{OA}-\mathrm{MNPs}$ was reported. ${ }^{24}$ The block copolymer was dissolved in N,N-dimethylformamide (DMF), a good solvent for both PS and PAA segments. This was mixed with a dispersion of MNPs in tetrahydrofuran (THF) at a defined ratio. When water, a selective non-solvent for both hydrophobic particles and PS blocks, was gradually added into this mixture, the NPs contained ABCs. This was surrounded by the cluster of MNPs or MPNPs. The cluster of MNPs entrapping the PS blocks became cores or seeds, whereas PAA blocks in the aqueous medium stabilized the resulting hybrid particles. However, some MNPs were incorporated into the MPNPs (ca. 23 particles per particle). To stabilize the particles and also protect the loss of MNPs, the PAA shell needed to be chemically crosslinked. ABCs with long hydrophilic chains can be alternately employed. An advantage of the steric-stabilized hybrid MPNPs without chemical crosslinking (caused by a thick hydrophilic shell) was the absence of mixing in the two solution phases in the former process which possibly introduced local inhomogeneity or aggregation. ${ }^{20}$ Recently, a low-energy and chemically-mild process for co-nanoprecipitation for SPIONPs and various ABCs, e.g., poly(ethylene glycol-b-2-hydroxypropyl methacrylate), P(PEG- $b$-HPMA) or P(EG- $b$-HPMA)- 
co-ethylene glycol dimethacrylate (P(EG- $b$-HPMA-co-EGDMA), has been developed. ${ }^{25}$ Based on the self-assembly of polymers during solvent switching, $10 \mathrm{wt} \%$ of SPIONPs could be loaded in all cases. When the hydrophilic PEG chain length was increased from 45 to 113 repeat units, the SPIONP arrangements considerably decreased, leading to the formation of relatively random-shaped SPIONP clusters.

In this study, well-defined MPNPs with a high loading of $70 \mathrm{wt} \%$ MNPs are prepared via the adapted chemically-mild process of co-self-assembly of OA-MNPs and an ABC with relatively longer hydrophilic blocks, i.e., $\mathrm{P}\left(\mathrm{S}_{27}-b-\mathrm{AA}_{120}\right)$. The $\mathrm{ABC}$ and $\mathrm{OA}-\mathrm{MNPs}$ are separately dissolved in different good solvents, i.e., water and THF or styrene, respectively. By adjusting the contents of OA-MNPs and $\mathrm{P}\left(\mathrm{S}_{27}-b-\mathrm{AA}_{120}\right)$ while applying ultrasonication, welldefined MPNPs, having aggregated MNPs as clusters or seeds encircled within the APC, are formed in a single-step. The synthesized MPNPs are characterized by transmission electron microscopy (TEM), dynamic light scattering (DLS), thermogravimetric analysis (TGA), attenuated total reflection Fourier transform-infrared spectroscopy (ATR-FTIR), and vibrating sample magnetometry (VSM). Controlled clustering of OA-MNPs inside the block copolymer (containing active functional groups) with high magnetic loading may result in an increase in magnetic hyperthermia for cancer therapy applications.

\section{MATERIALS AND METHODS}

\subsection{Materials}

Styrene (Sigma-Aldrich, Purum), iron (III) chloride $\left(\mathrm{FeCl}_{3}\right)$ (Riedel-deHaën), iron (II) chloride tetrahydrate $\left(\mathrm{FeCl}_{2} .4 \mathrm{H}_{2} \mathrm{O}\right)$ (Sigma Aldrich, Purum), 25\% ammonium hydroxide solution $\left(\mathrm{NH}_{4} \mathrm{OH}\right)$ (Merck, $\left.\mathrm{AR}\right)$, and oleic acid (OA) (Fluka, Natural from suet) were used as received. Preformed poly(styrene- $b$-acrylic acid), $\mathrm{P}\left(\mathrm{S}_{27}-b-\mathrm{AA}_{120}\right)$, was kindly provided by Prof. Charleux's group. ${ }^{26}$ Chemical structures and compositions of the copolymer was characterized 
by Fourier transform infrared (FTIR) and nuclear magnetic resonance (NMR) spectroscopy. The results are shown in Supporting Information (Figure S1). Deionized (DI) water was used throughout this work.

\subsection{Preparation and characterizations of MPNPs}

Magnetic nanoparticles coated with oleic acid (OA-MNPs) were prepared by the coprecipitation of $\mathrm{FeCl}_{3} / \mathrm{FeCl}_{2} .4 \mathrm{H}_{2} \mathrm{O}$ (molar ratio of 2:1) with $\mathrm{NH}_{4} \mathrm{OH}$ solution, as described elsewhere. ${ }^{11,17}$ Briefly, the precipitated MNPs were mixed with OA and then washed with ethanol to remove excess OA. The $2.4 \% \mathrm{w} / \mathrm{v}$ OA-MNPs dispersed in tetrahydrofuran (THF) and/or styrene $(1 \mathrm{~mL})$, were poured into a $0.1,0.5$, and $1.0 \mathrm{wt} \% \mathrm{P}\left(\mathrm{S}_{27}-b-\mathrm{AA}_{120}\right)$ dissolved in DI water $(10 \mathrm{~mL})$ at $\mathrm{pH} 10$, with ultrasonication at 70 (amplitude) for $10 \mathrm{~min}$. After slow evaporation of the organic solvent at room temperature, MPNPs were obtained.

The particle size, size distribution, and zeta potential of the prepared MPNPs were determined by a microelectrophoresis apparatus (Zetasizer; Malvern, Nano ZS). The morphology of MPNPs was studied by TEM (FEI, TECNAI G2), operated at an accelerating voltage of $120 \mathrm{kV}$. The magnetic content of MPNPs was determined by TGA (NETZSCH TG 209F1). ATR-FTIR (Perkin Elmer, FrontierTM) was employed to investigate their chemical structures and compositions. The saturation magnetization of the resulting particles was measured by using VSM (Lakeshore, 7403), under a magnetic field of up to $10 \mathrm{kOe}$, at room temperature.

The potential of the as-prepared MPNPs for use in magnetic hyperthermia application was explored by performing the heat induction study. The MPNP dispersed in DI water (2 mg.mL $\left.L^{-1}\right)$ was subjected into a high frequency induction heating machine (6.6 kW, HLQ induction, China) operating at $647 \mathrm{kHz}, 80 \mathrm{~A}$ current, using a single-turn induction coil having diameter of $27 \mathrm{~mm}$. The temperature of the sample solution was then measured by a fiber-optic 
temperature probe. The pure DI water was used as a control sample. After the treatments, the shape and morphology of the particles were reexamined under TEM.

\section{RESULTS AND DISCUSSIONS}

\subsection{Formation of MPNPs}

An important factor determining the success of the formation of stable hybrid particles containing MNPs in an ABC matrix is the compatibility of the MNP and ABC components. To modify the MNP surface for favorable interactions with the polymer host and decrease the attractive interactions among NPs, oleic acid (OA) was added for adsorption on the MNPs. The results show that the hydrophobic OA-MNPs (having an average size of $\sim 20 \mathrm{~nm}$ ) could be homogeneously dispersed in THF and styrene monomer (Supporting Information, Figure S2). In contrast, when dissolving the preformed amphiphilic $\mathrm{P}\left(\mathrm{S}_{27}-b-\mathrm{AA} \mathrm{A}_{120}\right)$ in an aqueous phase at $\mathrm{pH} 10$, a turbid solution was produced. It is believed that the turbid solution was caused by $\mathrm{ABC}$ micelle formation due to its amphiphilic character. ${ }^{27,28}$ However, the size of the polymeric micelles might be too small to be examined by DLS measurements. Moreover, the difference in the refractive index of the micelles and the medium might be low. The hydrophobic PS block might be in a collapsed state, minimizing its interactions with the aqueous phase. The asymmetric blocks of the copolymers with longer hydrophilic PAA segments prevented the aggregation of micelles, and hence, prevented the formation of NPs in an aqueous medium via steric effects. $^{25}$

The preparation of MPNPs is schematically shown in Figure 1. After OA-MNPs (dispersed in THF and/or styrene monomer) were added into the $\mathrm{ABC}$ aqueous solution, the mixture was separated into two phases. During the ultrasonic treatment, the solubility of OAMNPs was changed by water. The solubility of $\mathrm{P}\left(\mathrm{S}_{27}-b-\mathrm{AA}_{120}\right)$ was disturbed by THF and/or styrene monomer, which are good solvents for the hydrophobic PS blocks. The co-self- 
assembly of hydrophobic OA-MNPs with $\mathrm{P}\left(\mathrm{S}_{27}-b-\mathrm{AA}_{120}\right)$ induced the minimization of their energetically unfavorable interactions, resulting in the formation of MPNPs. Besides electrostatic stabilization, the interaction between the hydrophilic long PAA blocks and water molecules is responsible for the steric repulsion of the particles.

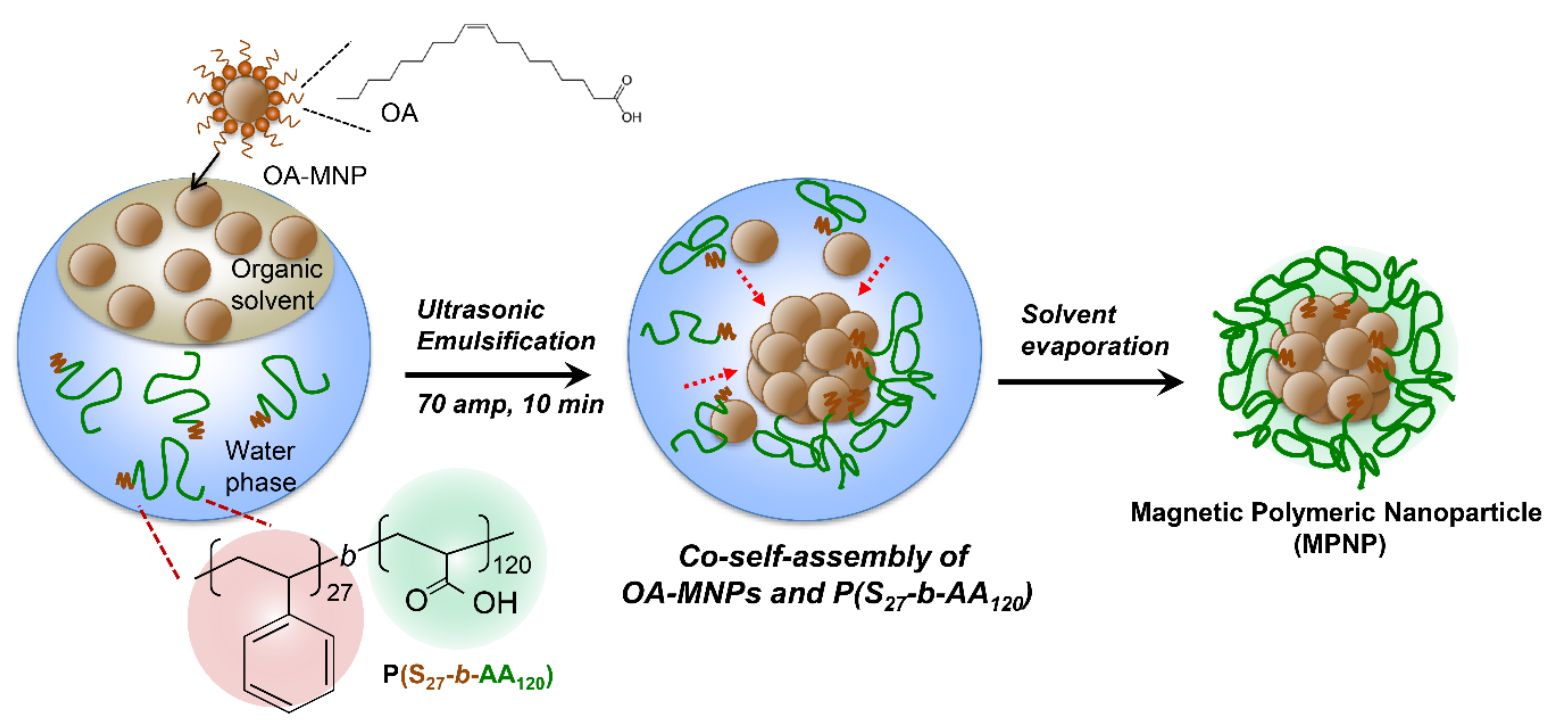

Figure 1 Scheme presenting the formation of MPNPs via co-self-assembly of hydrophobic OAMNPs and $\mathrm{P}\left(\mathrm{S}_{27}-b-\mathrm{AA}_{120}\right) ; \mathrm{amp}=$ amplitude

To optimize the recipe for providing well-defined MPNPs having high magnetic content, the effects of important factors, i.e., type of organic solvent for OA-MNPs, the $\mathrm{P}\left(\mathrm{S}_{27-}\right.$ $b$ - $\left.\mathrm{AA}_{120}\right)$ contents, and the OA-MNP:PS $27-b-\mathrm{AA}_{120}$ feed ratios on the properties of the resulting materials, were examined.

\subsubsection{Effects of type of organic solvent for OA-MNPS}

To examine the effects of solvent on the co-self-assembly structure, THF (solubility parameter or $\left.\delta=18.6 \mathrm{MPa}^{1 / 2}\right)$ and styrene monomer $\left(\delta=17.8 \mathrm{MPa}^{1 / 2}\right)$ were used as good solvents for the hydrophobic OA-MNPs $\left(\delta\right.$ of OA $\left.=17.4 \mathrm{MPa}^{1 / 2}\right)$ and PS segments $(\delta=19.0$ $\mathrm{MPa}^{1 / 2}$ ) of $\mathrm{ABC} \cdot .^{23,29,30}$ The morphology of the MPNPs, prepared from $0.1,0.5$, and $1.0 \mathrm{wt} \%$ 
$\mathrm{P}\left(\mathrm{S}_{27}-b-\mathrm{AA}_{120}\right)$ in $10 \mathrm{~mL}$ of DI water with a fixed amount of OA-MNPs at $2.4 \mathrm{wt} \%$ in $1 \mathrm{~mL}$ of THF or styrene monomer, were examined by TEM. The images are shown in Figure 2.

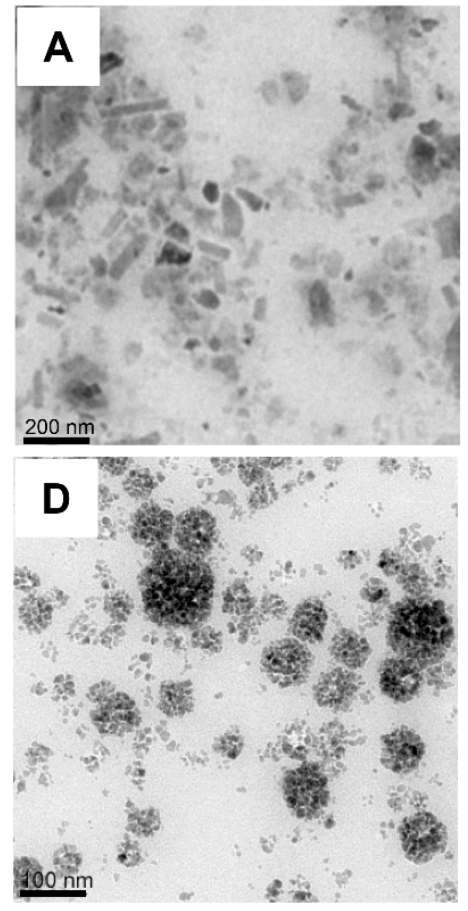

$0.1 \mathrm{wt} \%$
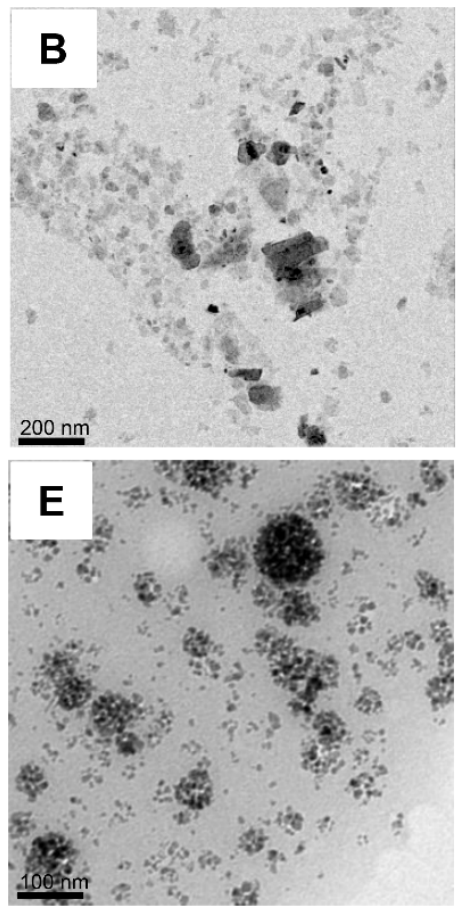

$0.5 \mathrm{wt} \%$

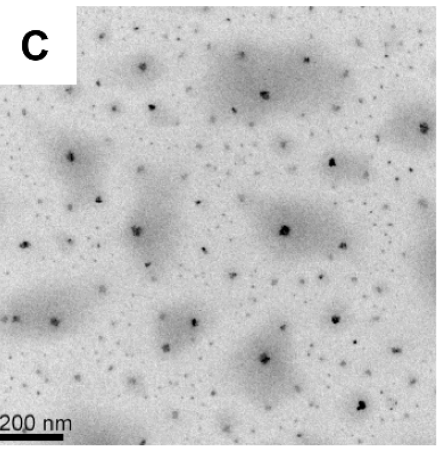

$\mathbf{F}$

$\mathrm{P}\left(\mathrm{S}_{27}-b-\mathrm{AA}_{120}\right)$ content

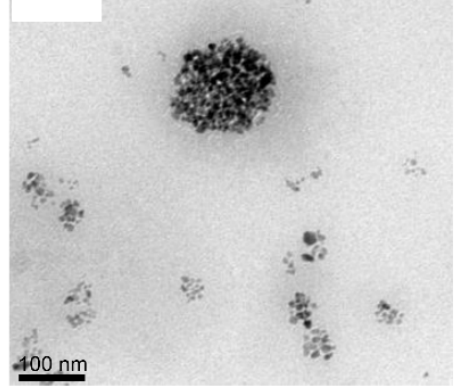

$1.0 \mathrm{wt} \%$

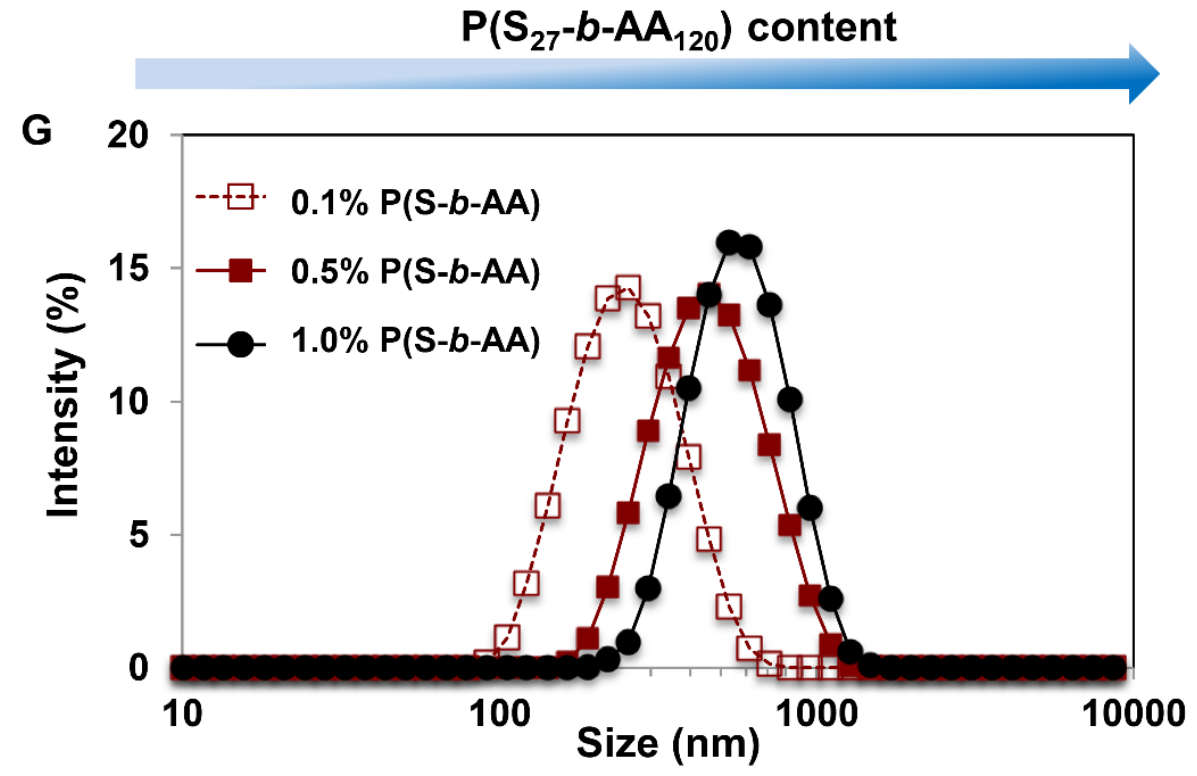

Figure 2 TEM images of the MPNPs prepared by using $2.4 \mathrm{wt} \%$ OA-MNPs dispersed in (A-

C) THF and (D-F) styrene monomer; $\mathrm{P}\left(\mathrm{S}_{27}-b-\mathrm{AA}_{120}\right)$ of $(\mathrm{A}, \mathrm{D}) 0.1 \mathrm{wt} \%$, $(\mathrm{B}, \mathrm{E}) 0.5 \mathrm{wt} \%$, and (C,F) $1.0 \mathrm{wt} \%$; (G) Hydrodynamic size of MPNPs dispersed in styrene 
It was observed that MPNPs were not generated when using THF as the solvent (Figure 2A-2C). However, the structure was effectively formed in the presence of styrene monomer, especially at low amounts of $\mathrm{P}\left(\mathrm{S}_{27}-b-\mathrm{AA}_{120}\right)$, i.e., $<0.5 \mathrm{wt} \%$ (Figure $2 \mathrm{D}$ and $\left.2 \mathrm{E}\right)$. This is likely due to the differences in the physical properties of these solvents, i.e., solubility, boiling point, and vapor pressure. ${ }^{16,30,31}$ Although the hydrophobic OA-MNPs and PS segments of ABC were miscible in both solvents, the lower boiling point of THF $\left(65-67^{\circ} \mathrm{C}\right)$ makes it vaporized at a much higher rate compared to the styrene monomer $\left(145{ }^{\circ} \mathrm{C}\right)$. Hence, the nucleationaggregation of OA-MNPs did not take place in the step of emulsification under ultrasonication. This is because the hydrophobicity of the NPs was not high enough to induce the assembly of the block copolymer. It was reported that in the absence of a block copolymer, hydrophobic magnetic $\gamma-\mathrm{Fe}_{2} \mathrm{O}_{3}$ NPs in THF flocculated when adding water as a non-solvent. ${ }^{24}$ In contrast, the remaining styrene in the system could act as a reservoir for hydrophobic OA-MNP, inducing the PS blocks to partially dissolve in the solvent pool by hydrophobic attractive forces. The coself-assembly of the two components led to the formation of non-uniform clusters of MPNPs because the equilibrium state in the solution was not fully achieved. Similarly, when a high amount of $\mathrm{P}\left(\mathrm{S}_{27}-b-\mathrm{AA}_{120}\right)(1.0 \mathrm{wt} \%)$ was employed, the $\mathrm{ABC}$ absorbed styrene monomer, generating solid copolymer particles without OA-MNPs. ${ }^{25}$ This hypothesis was supported by the results of the hydrodynamic size $\left(D_{h}\right)$ of the MPNPs prepared from different concentrations of the block copolymer, as shown in Figure $2 \mathrm{G}$. The $\mathrm{D}_{\mathrm{h}}$ value increased with an increase in the concentration of the ABC. However, this trend was not seen under TEM analysis, as shown in Figure 2D-2F.

\subsubsection{Effects of $O A-M N P s: P S_{27}-b-A A_{120}$ feed ratios}

To prepare well-defined MPNPs having high magnetic loading, the effects of the OA$\mathrm{MNP}: \mathrm{P}\left(\mathrm{S}_{27}-b-\mathrm{AA}_{120}\right)$ feed ratios on the structures and properties of the materials were 
examined, as summarized in Table 1. TEM images, as shown in Figure 3, reveal that the success of MPNP formation strongly depends on the contents of both MNPs and the ABC. At a low block copolymer content of $0.1 \mathrm{wt} \%$ and OA-MNPs of $60 \mathrm{wt} \%$ (P1-M60), MPNPs were not formed. With the use of low $\mathrm{P}\left(\mathrm{S}_{27}-b-\mathrm{AA}_{120}\right)$ contents, the $\mathrm{ABC}$ was not high enough to assembly the nucleation-aggregation of OA-MNPs, resulting in unstable OA-MNPs cluster. An increase in the $\mathrm{ABC}$ content to $1.0 \mathrm{wt} \%$, with 50, 60 and $70 \mathrm{wt} \%$ OA-MNPs (P10-M50, P10M60 and P10-M70, respectively) generated materials with a high density of OA-MNPs, surrounded by a large OA-MNP-free polymer core. When high ABC concentrations were employed, the hydrophobic OA-MNPs did not participate in the resulting polymer particles, possibly due to their incompatibility. In this case, the aggregation or fragmentation of free OAMNPs in the system was confirmed by the appearance of brown sediments at the bottom of the reactor. ${ }^{32}$ This agreed with previous work on the preparation of quantum dot polymeric NPs. PS, having a relatively low solubility in DMF, led to a compact PS core in the micelles. ${ }^{33}$ As a result, the quantum dot NPs were pulled out of the compact PS core. They were then located at the interface between the core and the shell during the assembly of $\mathrm{P}(\mathrm{S}-b-\mathrm{AA})$ particles. In our case, well-defined MPNPs were successfully formed when using $\mathrm{P}\left(\mathrm{S}_{27}-b-\mathrm{AA}_{120}\right)$ of 0.1 and 0.5 wt $\%$ with a $70 \mathrm{wt} \%$ magnetic content (P1-M70 and P5-M70). This is because the incorporation of high-load OA-MNPs increased the effective volume of the PS phase. In addition, the relative volume ratio between the hydrophilic (PAA) and the hydrophobic (PS and NPs) parts became more symmetric, and hence, appropriate for spherical particle formation. The results agreed with a previous report on the formation of NPs. The ABC with a high degree of hydrophilicity, i.e., poly(ethylene glycol- $b$-2-hydroxypropyl methacrylate-co-ethylene glycol dimethacrylate), (P(EG ${ }_{113}-b$-HPMA $50-c o-E_{\text {EDMA }}$.95 $)$ were incorporated with MNPs. ${ }^{25}$ NPs-induced nucleation of nanoprecipitation was observed in the presence of $\mathrm{P}_{\left(\mathrm{EG}_{113}-b-\mathrm{HPMA}\right.}$-co-EGDMA $\left.\mathrm{A}_{0.95}\right)$, whereas the $\mathrm{ABC}$ was unable to self-assemble. 
Table 1 Preparation conditions of hybrid MPNPs

\begin{tabular}{cccc}
\hline Sample names & $\begin{array}{c}\text { P(S27-b-AA120) } \\
(\mathbf{w t} \%)\end{array}$ & $\begin{array}{c}\text { OA-MNPs } \\
(\mathbf{w t} \%)\end{array}$ & $\begin{array}{c}\text { OA-MNPs* } \\
(\mathbf{w t \%} \text {, theory) }\end{array}$ \\
\hline P1-M60 & 0.1 & 1.5 & 60 \\
P1-M70 & 0.1 & 2.4 & 70 \\
P5-M60 & 0.5 & 7.5 & 60 \\
P5-M70 & 0.5 & 12 & 70 \\
P10-M50 & 1.0 & 10 & 50 \\
P10-M60 & 1.0 & 15 & 60 \\
P10-M70 & 1.0 & 24 & 70 \\
\hline
\end{tabular}

* Supporting Information (Table S1), for details of calculation 


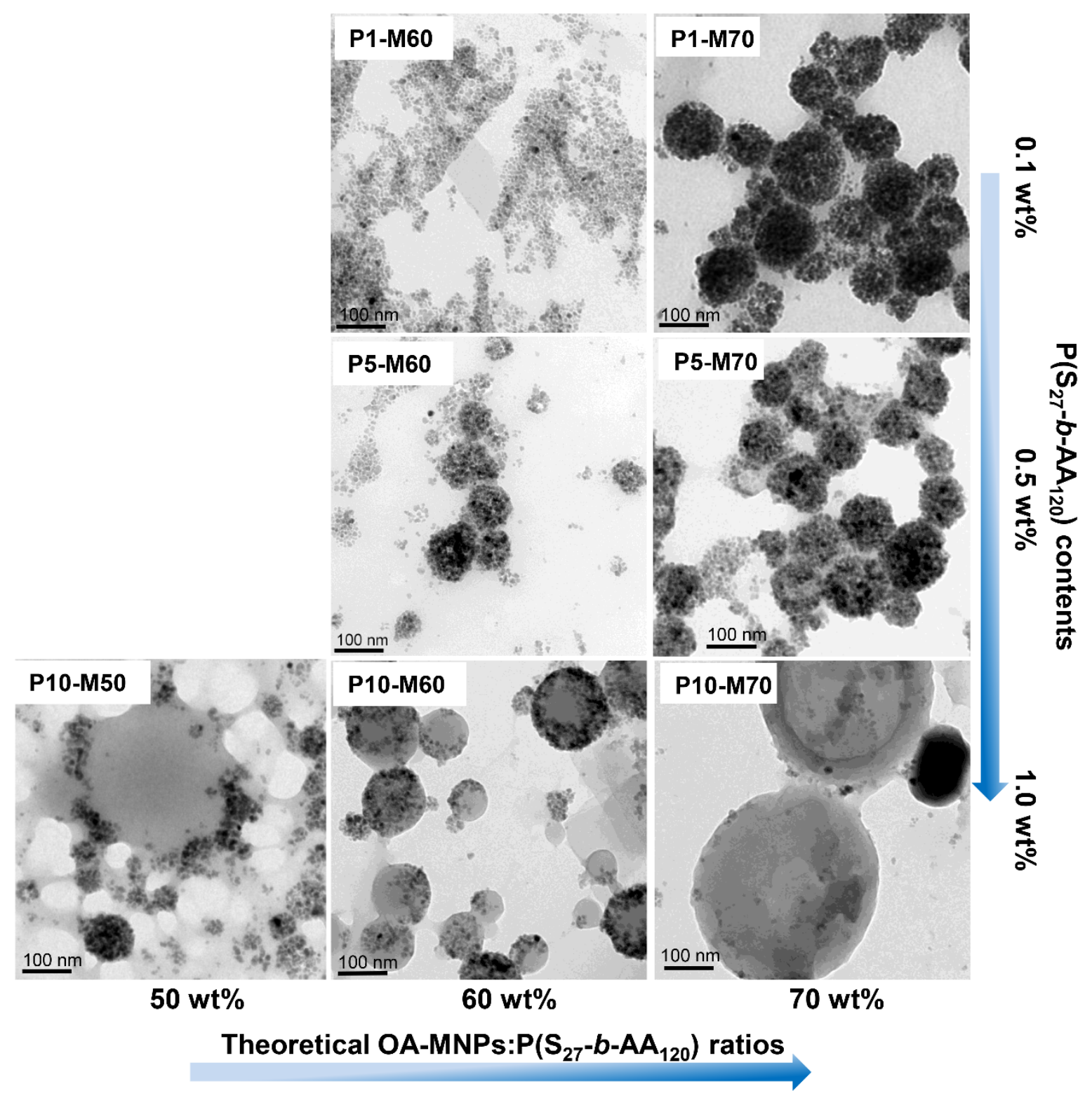

Figure 3 TEM images of MPNPs prepared from different weight fractions of OA-MNPs (50, 60 , and $70 \mathrm{wt} \%)$, and $\mathrm{P}\left(\mathrm{S}_{27}-b-\mathrm{AA}_{120}\right)$ contents $(0.1,0.5$, and $1.0 \mathrm{wt} \%)$

The corresponding TEM images of MPNPs were prepared by using $70 \mathrm{wt} \%$ OA-MNPs. The $\mathrm{P}\left(\mathrm{S}_{27}-b-\mathrm{AA}_{120}\right)$ contents of $0.1,0.3$, and $0.5 \mathrm{wt} \%$, called MPNP-1, MPNP-3, and MPNP5, respectively, are shown in Figure 4A. Figures $4 \mathrm{~B}$ and $4 \mathrm{C}$ display the TGA/derivative thermogravimetry (DTG), and DLS size distribution, in terms of hydrodynamic diameter, $\mathrm{D}_{\mathrm{h}}$. 

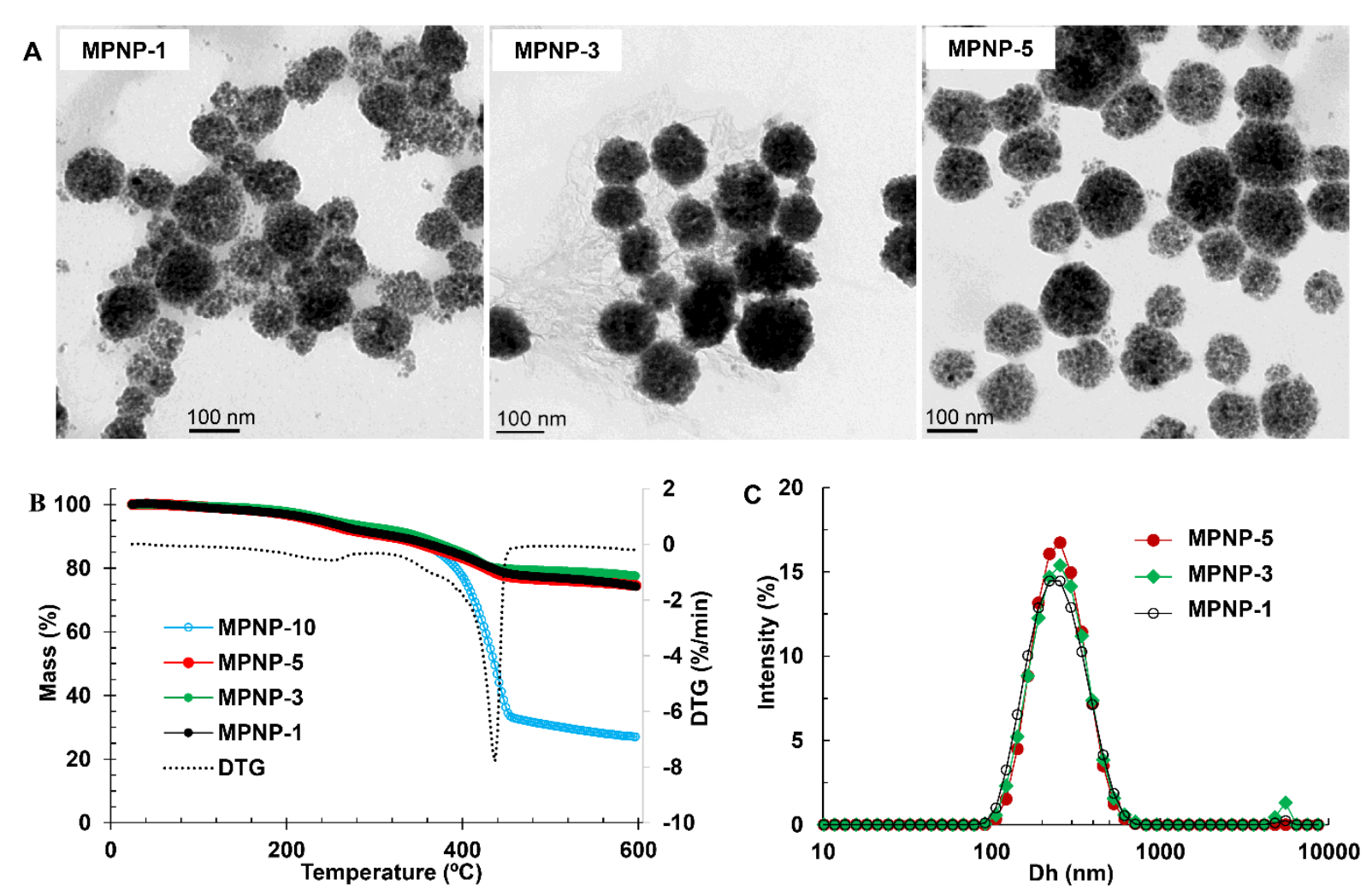

Figure 4 (A) TEM images, (B) TGA/DTG curves, and (C) DLS size distribution (hydrodynamic diameter, $\left.\mathrm{D}_{\mathrm{h}}\right)$ of MPNPs prepared from theoretical OA-MNPs: $\mathrm{P}\left(\mathrm{S}_{27}-b-\mathrm{AA}_{120}\right)$ ratio of $70 \mathrm{wt} \%$, with $\mathrm{ABC}$ contents of $0.1,0.3$, and $0.5 \mathrm{wt} \%$, coded as MPNP-1, MPNP-3, and MPNP-5, respectively.

TEM images in Figure 4A reveal spherical-shaped MPNPs having OA-MNP homogeneously distributed in the matrix of block copolymer particles. This is because the PS blocks are adsorbed onto the magnetic emulsion surfaces via hydrophobic interactions. The balance between the OA-MNPs (increasing the volume fraction of PS domains) and the $\mathrm{P}\left(\mathrm{S}_{27}-\right.$ $b$-AA ${ }_{120}$ ) contents maintains the spherical shape of the particles, while achieving high OA-MNP loading compositions. The long PAA blocks cause a thick hydrophilic shell layer, which effectively stabilized the MPNPs and prevented the loss of NPs without chemical crosslinking. ${ }^{20}$ After washing with DI water several times, TEM images of the materials still show spherical-shaped MPNPs, indicating strong entanglements of PAA chains in the shell. 
TGA thermograms, as shown in Figure 4B, exhibit 2 steps of weight loss. The first degradation step of $18.2 \mathrm{wt} \%$ at $200-400^{\circ} \mathrm{C}$ corresponds to the OA coated on the MNPs (Supporting Information, Figure S2). ${ }^{12,34}$ The major weight loss step at $436{ }^{\circ} \mathrm{C}$ was likely due to the degradation of the $\mathrm{P}\left(\mathrm{S}_{27}-b-\mathrm{AA}_{120}\right)$ matrix. ${ }^{11,12,35}$ The magnetic content obtained from TGA thermograms, compared with theoretical values and the $\mathrm{D}_{\mathrm{h}}$ results, are summarized in Table 2. A remaining weight of 74.3, 77.6, and $74.7 \mathrm{wt} \%$ of MNPs was found for MPNP-1, MPNP-3, and MPNP-5, respectively. These values are slightly higher than those from the theoretical calculations, due to the excluded OA molecules. This indicates a similar particle formation mechanism, which is also supported by their comparable hydrodynamic diameter $\left(D_{h}\right)$, with values of about $300 \mathrm{~nm}$. However, a much lower magnetic content was observed in the TGA thermogram of MPNP-10 (27.0 wt $\%)$, which is correlated with its distinct $\mathrm{D}_{\mathrm{h}}$ value of $916 \mathrm{~nm}$ and TEM image (Figure 3, sample P10-M70), in which OA-MNP-free polymer cores were observed. This indicates a different particle formation mechanism.

Table 2 Summary of MPNP properties, prepared by a fixed OA-MNP content of $70 \mathrm{wt} \%$ and $\mathrm{P}\left(\mathrm{S}_{27}-b-\mathrm{AA}_{120}\right)$ of $0.1,0.3,0.5$, and $1.0 \mathrm{wt} \%$

\begin{tabular}{|c|c|c|c|c|c|}
\hline Samples & $\begin{array}{c}\mathbf{P}\left(\mathbf{S}_{27}-b-\mathrm{AA}_{120}\right) \\
(\mathbf{w t} \%)\end{array}$ & $\begin{array}{l}\text { OA-MNPs } \\
(\mathbf{w t} \%)\end{array}$ & $\begin{array}{c}\text { OA-MNPs } \\
\text { (wt\%, theory) }\end{array}$ & $\begin{array}{c}\% \text { MNPs } \\
\text { (wt\%, TGA) }\end{array}$ & $D_{h}(n m)$ \\
\hline MPNP-1 & 0.1 & 2.4 & 70 & 74.3 & 309 \\
\hline MPNP-3 & 0.3 & 7.0 & 70 & 77.6 & 324 \\
\hline MPNP-5 & 0.5 & 12 & 70 & 74.7 & 326 \\
\hline MPNP-10 & 1.0 & 24 & 70 & 27.0 & 916 \\
\hline
\end{tabular}

The $D_{h}$ distribution curves of MPNPs determined from DLS measurements are displayed in Figure 4C. Monodisperse or narrow-size distribution curves with a low polydispersity index value of 0.1 were observed in all samples. ${ }^{36}$ Average sizes of 309,324 , and $326 \mathrm{~nm}$ were observed when the $\mathrm{P}\left(\mathrm{S}_{27}-b-\mathrm{AA}_{120}\right)$ contents of $0.1,0.3$, and $0.5 \mathrm{wt} \%$ were 
employed. The increase in the average size with increasing concentration of the block copolymer indicates the presence of this $\mathrm{ABC}$ on the particle surface by acting as a stabilizer for the magnetic clusters. ${ }^{37,38}$ With an increase in the concentration of $\mathrm{P}\left(\mathrm{S}_{27}-b-\mathrm{AA}_{120}\right)$, multilayer adsorption of the copolymer occurred as a result of van der Waals interactions in the hydrophobic phase and strong hydrogen bonding in the hydrophilic domains.

\subsection{Characterizations of MPNPs}

The existence of the PAA domain at the outer layer of MPNPs is shown by the results from FTIR spectra and the zeta potential of MPNP-5 as a function of $\mathrm{pH}$, as presented in Figures 5A and 5B. The characteristics bands at 2922 and $2852 \mathrm{~cm}^{-1}(\mathrm{C}=\mathrm{C}-\mathrm{H}$ stretching), 1557, 1450, and $1404 \mathrm{~cm}^{-1}\left(\mathrm{C}=\mathrm{C}\right.$ stretching), and 765 and $705 \mathrm{~cm}^{-1}$ (C-H out-of-plane bending of monosubstituted rings) confirm the presence of the PS domain. The bands at $3373 \mathrm{~cm}^{-1}(-\mathrm{OH}$ stretching) and $1704 \mathrm{~cm}^{-1}(\mathrm{C}=\mathrm{O}$ stretching mode $)$ indicate the carboxylic acid groups in the PAA segments. ${ }^{12,39}$ A broad band covering the $670-500 \mathrm{~cm}^{-1}$ region is attributed to the vibrational mode of $\mathrm{Fe}_{3} \mathrm{O}_{4}$ in the particles. Figure $5 \mathrm{~B}$ shows that the absolute zeta potential value of MPNP-5 particles is negative at $\mathrm{pH}>4$, due to the presence of $-\mathrm{COOH}$ in $\mathrm{PAA}(\mathrm{pH}>$ $\mathrm{pKa}$ for $-\mathrm{COO}^{-}$groups). For $\mathrm{pH}$ 6-10, high negative zeta potential values, which are significantly unchanged, were observed. This is likely due to the complete deprotonation of the carboxylic acid groups to carboxylate anions $\left(-\mathrm{COO}^{-}\right) .{ }^{27,39}$ This shows that MPNPs, stabilized by long solvated-block segments containing carboxylic acid groups, can be potentially used in a broad range of $\mathrm{pH}$ environments. 

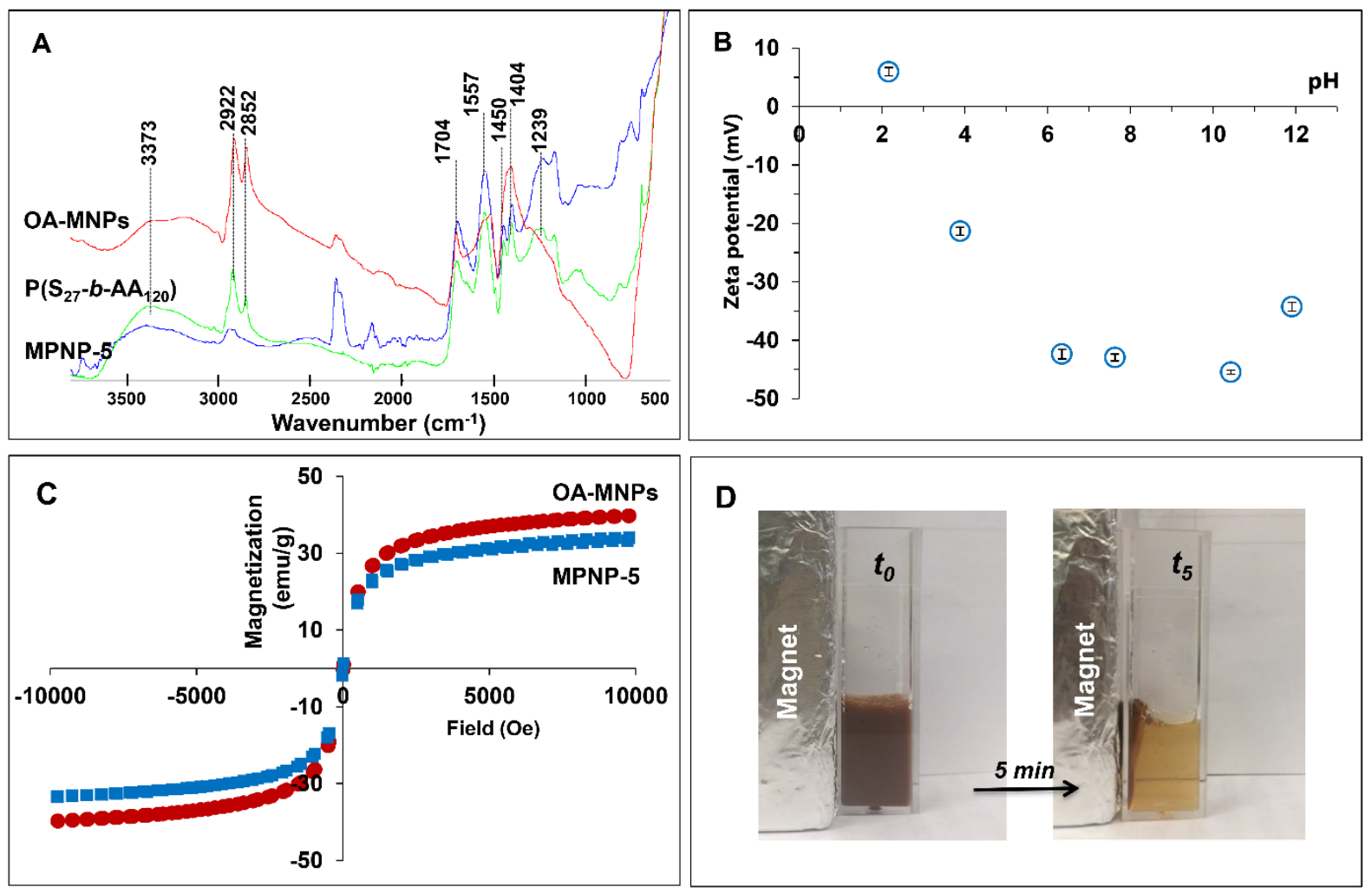

Figure 5 (A) FTIR spectra of $\mathrm{P}\left(\mathrm{S}_{27}-b-\mathrm{AA}_{120}\right)$, OA-MNPs, and MPNP-5, (B) zeta potential of MPNP-5, as a function of $\mathrm{pH}$ of the medium, (C) magnetization curves of OA-MNPs (red circles) and MPNP-5 (blue squares), and (D) photograph of magnetic field responses of MPNP-5 to an external magnet at room temperature

For applications in the biomedical fields, the magnetization versus applied magnetic field of OA-MNPs and MPNP-5 were determined by VSM at room temperature, as shown in Figure 5C. The absence of a hysteresis loop in both curves confirmed their superparamagnetic behavior. ${ }^{40}$ The lower $\mathrm{M}_{\mathrm{s}}$ value of MPNP-5 (34.0 emu/g), compared to that of the OA-MNP counterpart (39.7 emu/g) was due to the shielding effect of the $\mathrm{P}\left(\mathrm{S}_{27}-b-\mathrm{AA}_{120}\right)$ matrix. ${ }^{11} \mathrm{~A}$ fast separation rate of the prepared MPNPs from their dispersing medium by an external magnet was observed, as shown in Figure 5D. After removing the external magnet, a homogeneous brown suspension (without large aggregation or precipitation) was detected. The result shows the superparamagnetic properties and the magnetic separation ability of the prepared MPNPs. 
Under an alternating magnetic field (AMF), the magnetization of these superparamagnetic particles randomly flips between the parallel and antiparallel directions, and hence, heat was rapidly generated. Therefore, the materials can be used in vivo to raise the temperature of tumor tissues, which are more sensitive to a sudden increase in temperature than healthy cells, to destroy the pathological cells by a hyperthermia process. ${ }^{5,6}$ For further use of the MPNPs in the magnetic hyperthermia for cancer therapy, heat induction of the as-prepared MPNP-5 was preliminary examined. When MPNP-5 (2 mg.mL $\left.\mathrm{mL}^{-1}\right)$ was subjected to an AMF $(647 \mathrm{kHz})$, the temperature rapidly increased from room temperature to $45 \pm 5{ }^{\circ} \mathrm{C}$ within $60 \mathrm{~s}$. This phenomenon might attribute to both high superparamagnetic nanoparticles loading with high $\mathrm{M}_{\mathrm{s}}$ value and their monodispersity. As previously reported, the inductive heating properties, including the $\mathrm{M}_{\mathrm{s}}$ value, of alginate-chitosan microspheres loaded with monodispersed $14 \mathrm{~nm}$-SPIONPs were strongly associated with the concentration of the SPIONPs. ${ }^{9}$ The time required to raise the temperature to $42{ }^{\circ} \mathrm{C}$ was approximately 203,230 , 283,327 and $4500 \mathrm{~s}$ for the materials with SPIONP loadings of $0.50,0.45,0.38,0.29$, and 0.18 mg. $\mathrm{mL}^{-1}$, respectively.

To examine the stability of the as-prepared MPNPs and avoid the possible breakage of MPNPs or leakage of SPIONPs that may affect the material's practical use, the shape and morphology of MPNPs was reexamined after the AFM treatments. TEM images as shown in Figure 6 indicated that the treated MPNP-5 particles retain well-defined shape and morphology without damage or distort, reflecting that the heat generated by the AMF treatment has negligible effects on the as-prepared MPNP structures. This is likely attributed to both the strong hydrophobic interactions of OA-MNPs and hydrophobic PS segments and the entanglements of PAA chains in the shell, without chemical crosslinking. Moreover, the styrene phase may polymerize, generating PS blocks which may be strongly fixed into the magnetic clusters due to redox polymerization. ${ }^{41}$ 

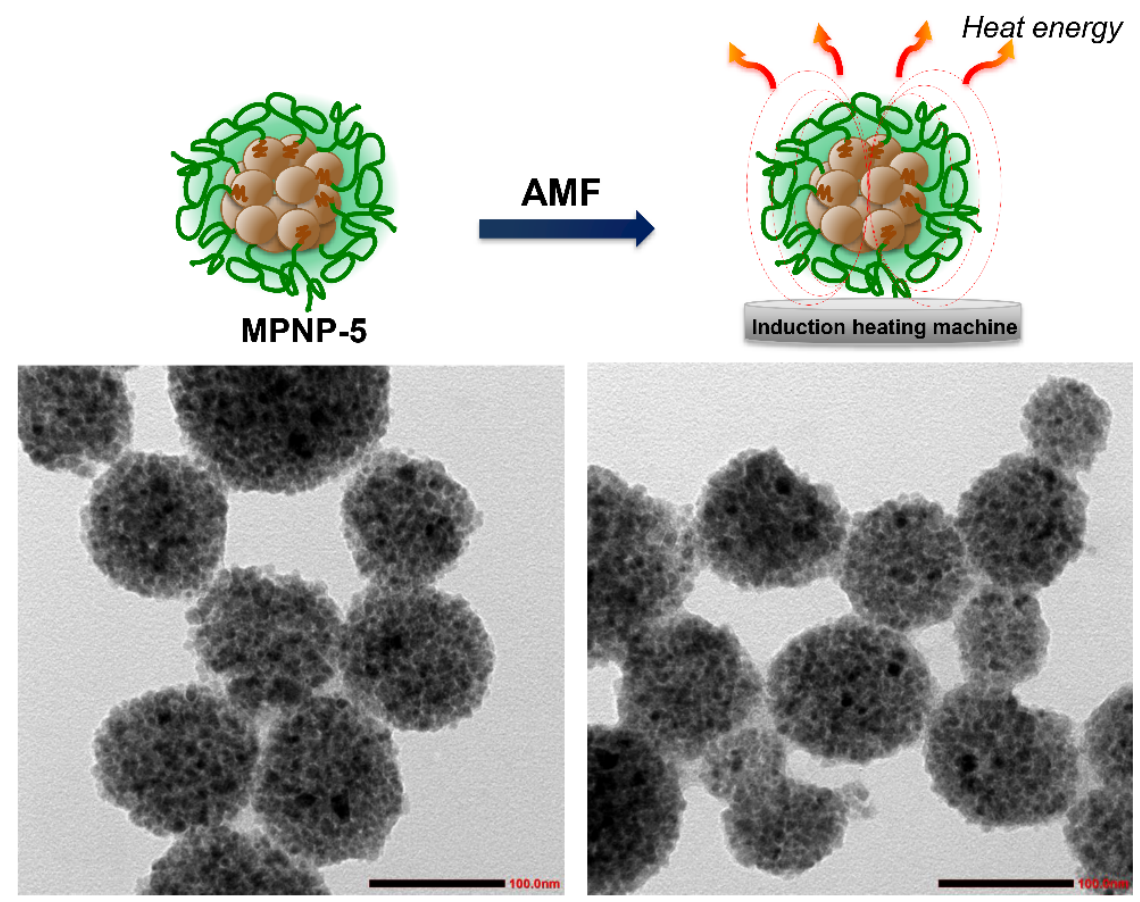

Figure 6 TEM image of MPNP-5 after AMF treatments

\section{Conclusions}

Well-defined MPNPs $\left(D_{h} \sim 320 \mathrm{~nm}\right)$ that have a high magnetic content $(70 \mathrm{wt} \%)$ and superparamagnetic were successfully prepared by using a chemically-mild process of co-selfassembly of hydrophobic OA-MNPs and amphiphilic $\mathrm{P}\left(\mathrm{S}_{27}-b-\mathrm{AA}_{120}\right)$ in an aqueous phase. The MPNPs were generated by controlling the type of solvent for OA-MNPs, the feed ratio of OAMNPs to the $\mathrm{ABC}$, and the balance of the weight fraction of OA-MNPs at $70 \mathrm{wt} \%$ dispersed in styrene, and the $\mathrm{ABC}$ contents in a range of $0.1-0.5 \mathrm{wt} \%$. The use of amphiphilic $\mathrm{P}\left(\mathrm{S}_{27}-b-\right.$ $\mathrm{AA}_{120}$ ) that have longer hydrophilic PAA blocks could stabilize the particles and protect against the loss of OA-MNPs without chemical crosslinking. More importantly, the as-prepared nanoparticles possess monodispersity, high loading of superparamagnetic nanoparticles, which are highly responsive to an external magnetic field, and can efficiently generate heat under the application of an AMF. The presence of abundant carboxylic groups of the particles not only enables their magnetically-targeting performance, but also further functionalization for high 
selectivity toward cells. The synthesized MPNPs have a high potential for use as magnetic hyperthermia for cancer therapy applications.

\section{Conflicts of interest}

The authors declare no competing financial interest.

\section{Acknowledgments}

This research project is supported by The New Researcher Grant (MRG6280141) from The Thailand Research Fund (TRF) and Office of the Higher Education Commission (OHEC) to C.K. and the Program Management Unit for Human Resources \& Institutional Development, Research and Innovation (grant number B05F630059) to P.T. The authors are grateful for support from the Center of Excellence in Materials and Plasma Technology (CoE M@P Tech), Thammasat University, and Prof. Bernadette Charleux for the supply of $\mathrm{P}\left(\mathrm{S}_{27}-b-\mathrm{AA}_{120}\right)$ samples.

\section{Supporting Information}

1H NMR spectrum of $\mathrm{P}\left(\mathrm{S}_{27}-b-\mathrm{AA}_{120}\right)$, The theoretical OA-MNP weight fraction calculation, TEM image (A) and TGA thermogram (B) of OA-MNPs

\section{References}

1. Shapiro EM. Biodegradable, Polymer Encapsulated, Metal Oxide Particles for MRIbased Cell Tracking. Magn Reson Med. 2015;73(1):376-389.

2. Gauger AJ, Hershberger KK, Bronstein LM. Theranostics Based on Magnetic Nanoparticles and Polymers: Intelligent Design for Efficient Diagnostics and Therapy. Front Chem. 2020;8(July):1-7. 
3. Fortuni B, Inose T, Ricci M, Fujita Y, Zundert IV, Masuhara A, Fron E, Mizuno H, Latterini L, Rocha S, Uji-i H. Polymeric Engineering of Nanoparticles for Highly Efficient Multifunctional Drug Delivery Systems. Sci Rep. 2019;9(1):1-13.

4. Balasubramanian S, Ravindran Girija A, Nagaoka Y, Fukuda T, Iwai S, Kizhikkilot V, Kato K, Maekawa T, Nair SD. An “All in One” Approach for Simultaneous Chemotherapeutic, Photothermal and Magnetic Hyperthermia Mediated by Hybrid Magnetic Nanoparticles. RSC Adv. 2015;5(32):25066-25078.

5. Liu X, Zheng J, Sun W, Zhao X, Li Y, Gong N, Wang Y, Ma X, Zhang T, Zhao LY, Hou Y, Wu Z, Du Y, Fan H, Tian J, Liang XJ. Ferrimagnetic Vortex NanoringMediated Mild Magnetic Hyperthermia Imparts Potent Immunological Effect for Treating Cancer Metastasis. ACS Nano. 2019;13(8):8811-8825.

6. Chang D, Lim M, Goos JACM, Qiao R, Ng YY, Mansfeld FM, Jackson M, Davis TP, Kavallaris M. Biologically Targeted Magnetic Hyperthermia: Potential and Limitations. Front Pharmacol. 2018;9(AUG).

7. Liu X, Zhang Y, Wang Y, Zhu W, Li G, Ma X, Zhang Y, Chen S, Tiwari S, Shi K, Zhang S, Fan HM, Zhao YX, Liang X-J. Comprehensive Understanding of Magnetic Hyperthermia for Improving Antitumor Therapeutic Efficacy. Theranostics. 2020;10(8):3793-3815.

8. Liu XL, Ng CT, Chandrasekharan P, Yang HT, Zhao LY, Peng E, Lv YB, Xiao W, Fang J, Yi JB, Zhang H, Chuang K-H, Bay BH, Ding J, Fan HM. Synthesis of Ferromagnetic Fe0.6Mn0.4O Nanoflowers as a New Class of Magnetic Theranostic Platform for In Vivo T1-T2 Dual-Mode Magnetic Resonance Imaging and Magnetic Hyperthermia Therapy. Adv Healthc Mater. 2016;5(16):2092-2104.

9. Xue W, Liu XL, Ma H, Xie W, Huang S, Wen H, Jing G, Zhao L, Liang X-J, Fan HM. AMF Responsive DOX-loaded Magnetic Microspheres: Transmembrane Drug Release 
Mechanism and Multimodality Postsurgical Treatment of Breast Cancer. J Mater Chem B. 2018;6(15):2289-2303.

10. Liu X, Lu Y. Tailoring Emulsion Polymerization for High-Yield Synthesis of Tween 80 Stabilized Magnetic Cross-Linked Polystyrene Nanocomposite Particles. Ind Eng Chem Res. 2019;58(19):8140-8147.

11. Charoenmark L, Polpanich D, Thiramanas R, Tangboriboonrat P. Preparation of Superparamagnetic Polystyrene-based Nanoparticles Functionalized by Acrylic Acid. Macromol Res. 2012;20(6):590-596.

12. Kaewsaneha C, Opaprakasit P, Polpanich D, Smanmoo S, Tangboriboonrat P. Immobilization of Fluorescein Isothiocyanate on Magnetic Polymeric Nanoparticle Using Chitosan as Spacer. J Colloid Interface Sci. 2012;377(1):145-152.

13. Zhou M, Zou J, Gu Y, Yi RJ, Tu H. Preparation of Magnetic Polymer Nanosphere and Its Profile Control. J Dispers Sci Technol. 2020;41(4):557-565.

14. Braconnot S, Eissa MM, Elaissari A. Morphology Control of Magnetic Latex Particles Prepared from Oil in Water Ferrofluid Emulsion. Colloid Polym Sci. 2013;291(1):193203.

15. Rahman MM, Montagne F, Fessi H, Elaissari A. Anisotropic Magnetic Microparticles from Ferrofluid Emulsion. Soft Matter. 2011;7(4):1483-1490.

16. Kaewsaneha C, Bitar A, Tangboriboonrat P, Polpanich D, Elaissari A. FluorescentMagnetic Janus Particles Prepared via Seed Emulsion Polymerization. J Colloid Interface Sci. 2014;424:98-103.

17. Bitar A, Kaewsaneha C, Eissa MM, Jamshaid T, Tangboriboonrat P, Polpanich D, Elaissari A. Ferrofluids : From Preparation to Biomedical Applications. J Colloid Sci Biotechnol. 2014;3(1):3-18.

18. Chen K, Zhu Y, Zhang Y, Li L, Lu Y, Guo X. Synthesis of Magnetic Spherical 
Polyelectrolyte Brushes. Macromolecules. 2011;44(3):632-639.

19. Jamshaid T, Eissa MM, Lelong Q, Bonhommé A, Augsti G, Zine N, Errachid A, Elaissari A. Tailoring of Carboxyl-decorated Magnetic Latex Particles Using Seeded Emulsion Polymerization. Polym Adv Technol. 2017;28(9):1088-1096.

20. Wang J, Li W, Zhu J. Encapsulation of Inorganic Nanoparticles into Block Copolymer Micellar Aggregates: Strategies and Precise Localization of Nanoparticles. Polymer. 2014;55(5):1079-1096.

21. La Porta A, Sánchez-Iglesias A, Altantzis T, Bals S, Grzelczak M, Liz-Marzán LM. Multifunctional Self-assembled Composite Colloids and Their Application to SERS Detection. Nanoscale. 2015;7(23):10377-10381.

22. Grzelczak M, Sánchez-Iglesias A, Liz-Marzán LM. A General Approach toward Polymer-coated plasmonic nanostructures. CrystEngComm. 2014;16(40):9425-9429.

23. Hickey RJ, Haynes AS, Kikkawa JM, Park SJ. Controlling the Self-assembly Structure of Magnetic Nanoparticles and Amphiphilic Block-copolymers: From Micelles to Vesicles. J Am Chem Soc. 2011;133(5):1517-1525.

24. Kim BS, Qiu JM, Wang JP, Taton TA. Magnetomicelles: Composite Nanostructures from Magnetic Nanoparticles and Cross-linked Amphiphilic Block Copolymers. Nano Lett. 2005;5(10):1987-1991.

25. Giardiello M, Hatton FL, Slater RA, Chambon P, North J, Peacock AK, He T, McDonald TO, Owen A, Rannard SP. Stable, Polymer-directed and SPION-nucleated Magnetic Amphiphilic Block Copolymer Nanoprecipitates with Readily Reversible Assembly in Magnetic Fields. Nanoscale. 2016;8:7224-7231.

26. Burguière C, Pascual S, Bui C, Vairon J-P, Charleux B, Davis KA, Matyjaszewski K, Bétremieux I. Block Copolymers of Poly(styrene) and Poly(acrylic acid) of Various Molar Masses, Topologies, and Compositions Prepared via Controlled/Living Radical 
Polymerization. Application as Stabilizers in Emulsion Polymerization.

Macromolecules. 2001;34(13):4439-4450.

27. Swift T, Swanson L, Geoghegan M, Rimmer S. The pH-responsive Behaviour of Poly(acrylic acid) in Aqueous Solution is Dependent on Molar Aass. Soft Matter. 2016;12(9):2542-2549.

28. Geng Z, Cheng Z, Zhu Y, Jiang W. Controllable Cooperative Self-Assembly of PS-bPAA/PS-b-P4VP Mixture by Tuning the Intercorona Interaction. J Phys Chem B. 2016;120(24):5527-5533.

29. Cai Y, Yan W, Peng X, Liang M, Yu L, Zou H. Influence of Solubility Parameter Difference between Monomer and Porogen on Structures of Poly(acrylonitrile-styrenedivinylbenzene) Resins. J Appl Polym Sci. 2019;136(3):1-7.

30. Choucair A, Lavigueur C, Eisenberg A. Polystyrene-b-Poly(acrylic acid) Vesicle Size Control Using Solution Properties and Hydrophilic Block Length. Langmuir. 2004;20(10):3894-3900.

31. Zheng J, He A, Li J, Xu J, Han CC. Studies on the Controlled Morphology and Wettability of Polystyrene Surfaces by Electrospinning or Electrospraying. Polymer. 2006;47(20):7095-7102.

32. Kaewsaneha C, Tangboriboonrat P, Polpanich D, Eissa M, Elaissari A. Anisotropic Janus Magnetic Polymeric Nanoparticles Prepared via Miniemulsion Polymerization. $J$ Polym Sci Part A Polym Chem. 2013;51(22):4779-4785.

33. Sanchez-Gaytan BL, Cui W, Kim YJ, Mendez-Polanco MA, Duncan TV, Fryd M, Wayland BB, Park S-J. Interfacial Assembly of Nanoparticles in Discrete BlockCopolymer Aggregates. Angew Chemie - Int Ed. 2007;46(48):9235-9238.

34. Gong T, Yang D, Hu J, Yang W, Wang C, Lu JQ. Preparation of Monodispersed Hybrid Nanospheres with High Magnetite Content from Uniform Fe3O4 Clusters. 
Colloids Surfaces A Physicochem Eng Asp. 2009;339(1-3):232-239.

35. Ramírez LP, Landfester K. Magnetic Polystyrene Nanoparticles with a High Magnetite Content Obtained by Miniemulsion Processes. Macromol Chem Phys. 2003;204(1):2231.

36. Dobhal A, Kulkarni A, Dandekar P, Jain R. A Microreactor-based Continuous Process for Controlled Synthesis of Poly-Methyl-Methacrylate-Methacrylic Acid (PMMA) Nanoparticles. J Mater Chem B. 2017;5(18):3404-3417.

37. Vshivkov SA, Soliman TS, Kluzhin ES, Kapitanov AA. Structure of Poly(acrylic acid), poly(methacrylic acid) and Gelatin Solutions. J Mol Liq. 2019;294:111551.

38. Jeon SJ, Hong WH. Effects of Poly(acrylic acid) and Poly(ethylene oxide) Adsorption on the Stability of Alumina Suspension. Korean J Chem Eng. 2003;20:916-921.

39. Nuasaen S, Tangboriboonrat P. Highly Charged Hollow Latex Particles Prepared via Seeded Emulsion Polymerization. J Colloid Interface Sci. 2013;396:75-82.

40. Sandler SE, Fellows B, Thompson Mefford O. Best Practices for Characterization of Magnetic Nanoparticles for Biomedical Applications. Anal Chem. 2019;91(22):1415914169.

41. Qiu G, Wang Q, Wang C, Lau W, Guo Y. Polystyrene/Fe3O4 Magnetic Emulsion and Nanocomposite Prepared by Ultrasonically Initiated Miniemulsion Polymerization. Ultrason Sonochem. 2007;14(1):55-61. 


\section{Supporting Information}

\section{Poly(styrene- $b$-acrylic acid) Nanoparticles with High Magnetic Loading for Magnetic Hyperthermia Cancer Therapy}

Chariya Kaewsaneha ${ }^{\mathrm{a}, *}$, Abdelhamid Elaissari ${ }^{\mathrm{b}}$, Pakorn Opaprakasit ${ }^{\mathrm{a}}$, Paiboon Sreearunothai ${ }^{\mathrm{a}}$ and Pramuan Tangboriboonrat ${ }^{\mathrm{c}}$

${ }^{a}$ School of Bio-Chemical Engineering and Technology, Sirindhorn International Institute of Technology (SIIT), Thammasat University, Pathum Thani 12121, Thailand

${ }^{b}$ Univ Lyon, University Claude Bernard Lyon-1, CNRS, ISA-UMR 5280, F-69622 Lyon, France

${ }^{c}$ Department of Chemistry, Faculty of Science, Mahidol University, Rama 6 Road, Phya Thai, Bangkok 10400, Thailand

Corresponding Author's E-mail: chariya@siit.tu.ac.th 


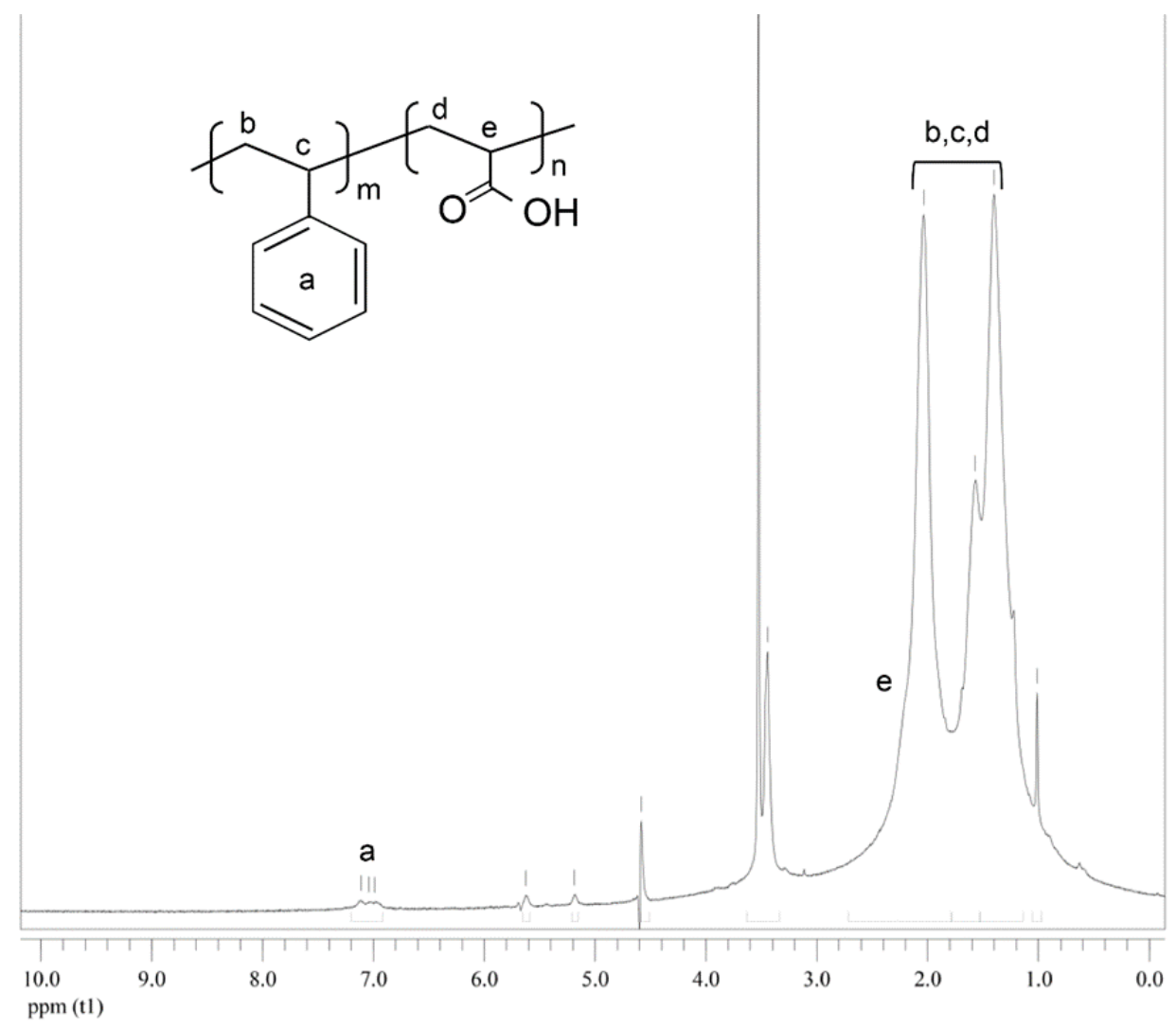

Figure $\mathrm{S} 1$ 1H NMR spectrum of $\mathrm{P}\left(\mathrm{S}_{27}-b-\mathrm{AA}_{120}\right)$ 
For preparation of MPNP, the $2.4 \% \mathrm{w} / \mathrm{v}$ OA-MNPs dispersed in styrene $(1 \mathrm{~mL})$ were poured into a $0.1,0.5$, and $1.0 \mathrm{wt} \% \mathrm{P}\left(\mathrm{S}_{27}-b-\mathrm{AA}_{120}\right)$ dissolved in DI water $(10 \mathrm{~mL})$ at $\mathrm{pH} 10$, with ultrasonication at 70 (amplitude) for $10 \mathrm{~min}$. After slow evaporation of the organic solvent at room temperature, MPNPs were obtained.

The theoretical weight fraction of OA-MNPs embedded in the prepared hybrid MPNPs was calculated from the following equitation;

$$
\% O A-M N P S=\frac{W_{M}}{W_{M}+W_{P}} \times 100
$$

where $W_{M}$ and $W_{P}$ are amount of OA-MNPs and $\mathrm{P}\left(\mathrm{S}_{27}-b-\mathrm{AA}_{120}\right)$ used in the system.

Table S1 Preparation conditions of hybrid MPNPs and theoretical weight fraction of OA-MNPs embedded in the MPNPs

\begin{tabular}{|c|c|c|}
\hline $\begin{array}{c}\mathbf{P}\left(\mathbf{S}_{\mathbf{2 7}}-\boldsymbol{b} \text {-AA } \mathbf{A 2 0}\right) \\
(\mathrm{wt} \% \text {, in } 10 \mathrm{~mL} \text { DI water })\end{array}$ & $\begin{array}{c}\text { OA-MNPs } \\
(\mathrm{wt} \% \text {, in } 1 \mathrm{~mL} \text { styrene })\end{array}$ & $\begin{array}{c}\text { OA-MNPs } \\
\text { (wt } \% \text {, theory, } \\
\text { embedded in MPNP })\end{array}$ \\
\hline 0.1 & 2.4 & 71 \\
\hline 0.5 & 2.4 & 32 \\
\hline 1.0 & 2.4 & 19 \\
\hline
\end{tabular}



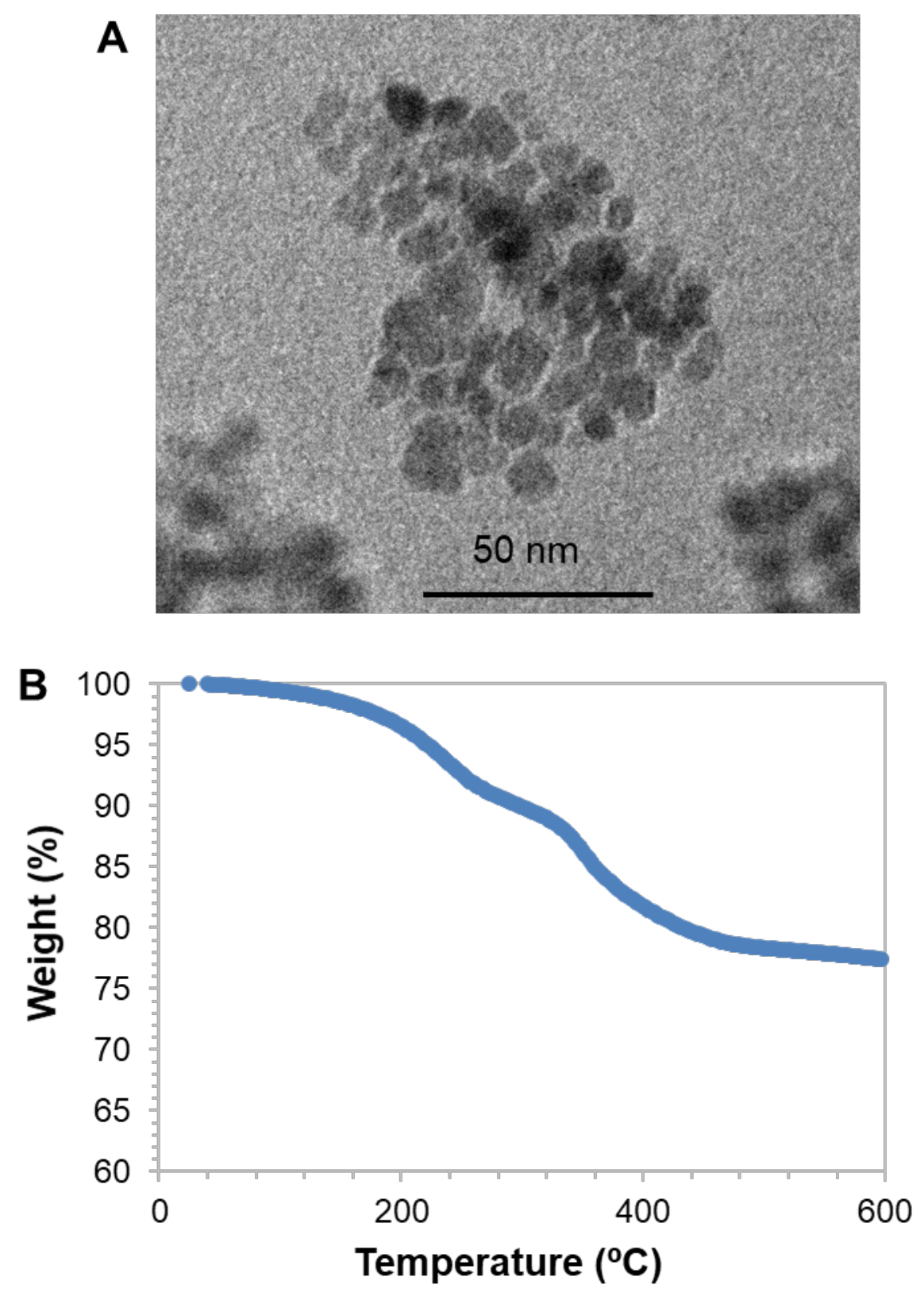

Figure S2 TEM image (A) and TGA thermogram (B) of OA-MNPs 